\title{
A modified approach for endoscopic ultrasound-guided management of disconnected pancreatic duct syndrome via drainage of a communicating collection
}

Endoscopic ultrasound (EUS)-guided pancreaticogastrostomy to drain the viable upstream pancreas in patients with disconnected pancreatic duct syndrome is technically challenging [1]. Here, we present a modified EUS-guided pancreaticogastrostomy via drainage of a fluid collection in communication with the duct disruption ( $\vee$ Video 1 ).

The first patient is a 63-year-old woman with recurrent acute pancreatitis referred for management of disconnected pancreatic duct syndrome. EUS revealed a 3.9-cm pancreatic body necrotic fluid collection ( $>$ Fig. 1 ) and a mildly dilated main pancreatic duct in the tail. On contrast injection into the dilated duct, the necrotic collection also filled with contrast, indicating communication with the

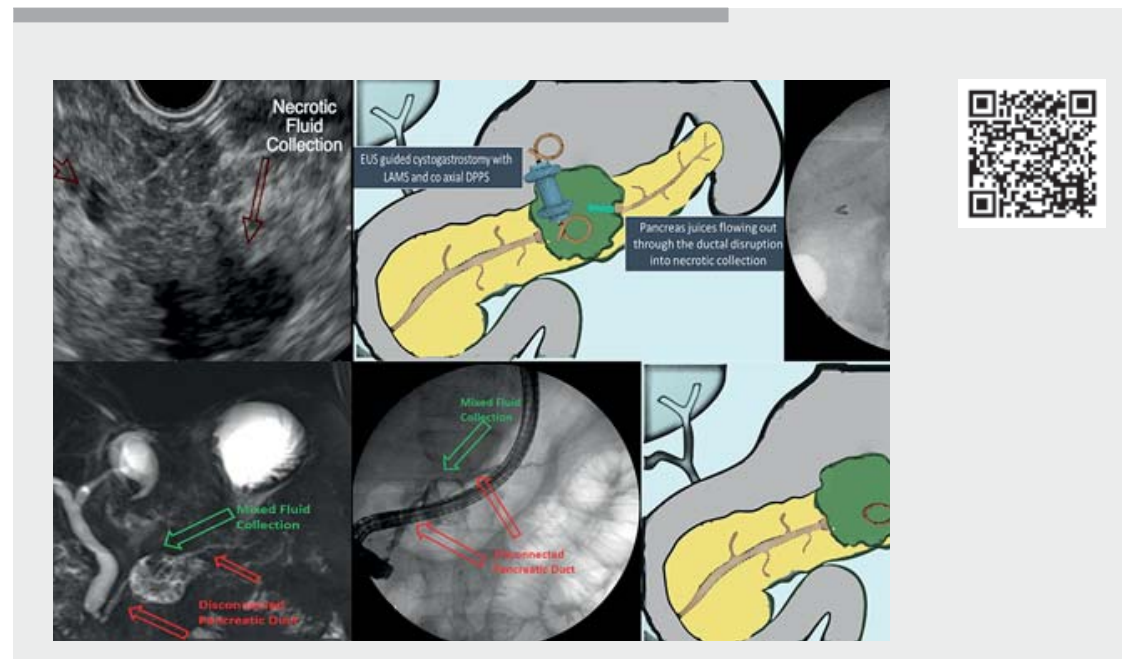

$\nabla$ Video 1 Endoscopic ultrasound-guided management of disconnected pancreatic duct syndrome via drainage of a communicating collection.
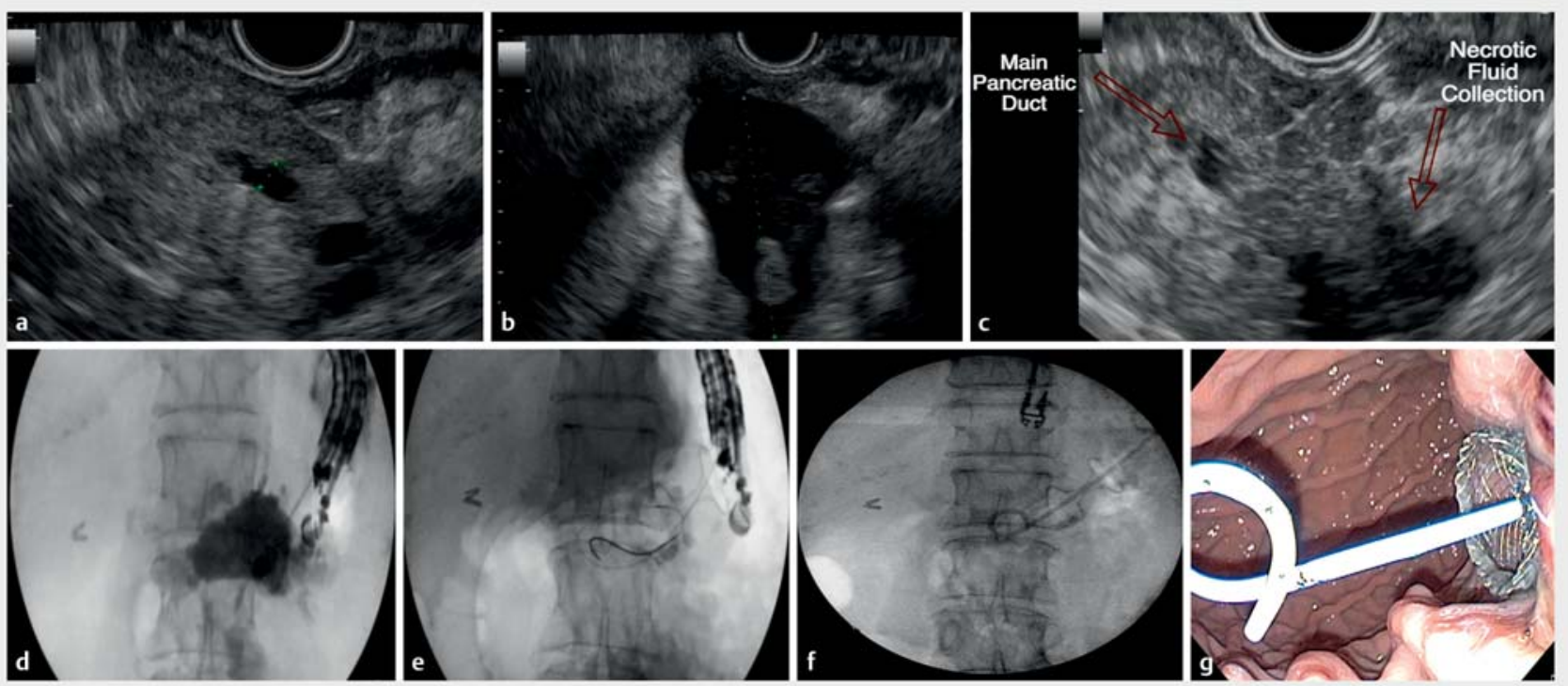

- Fig. 1 Endoscopic ultrasound-guided cystogastrostomy for disconnected pancreatic duct syndrome. a Endosonographic view of mildly dilated main pancreatic duct in the tail of the pancreas. $\mathbf{b}$ Endosonographic view of necrotic fluid collection in the body of pancreas. $\mathbf{c}$ Endosonographic view of contrast injection into the main pancreatic duct showing communication with necrotic fluid collection. $\mathbf{d}$ Fluoroscopic view of needle puncture of necrotic fluid collection. e Fluoroscopic view of guidewire coiling in the necrotic fluid collection, $\mathbf{f}$ Fluoroscopic view of the lumen-apposing metal stent (LAMS) and coaxial double-pigtail plastic stent creating the cystogastrostomy. $\mathbf{g}$ Endoscopic view of the LAMS and double-pigtail plastic stent creating the cystogastrostomy. 


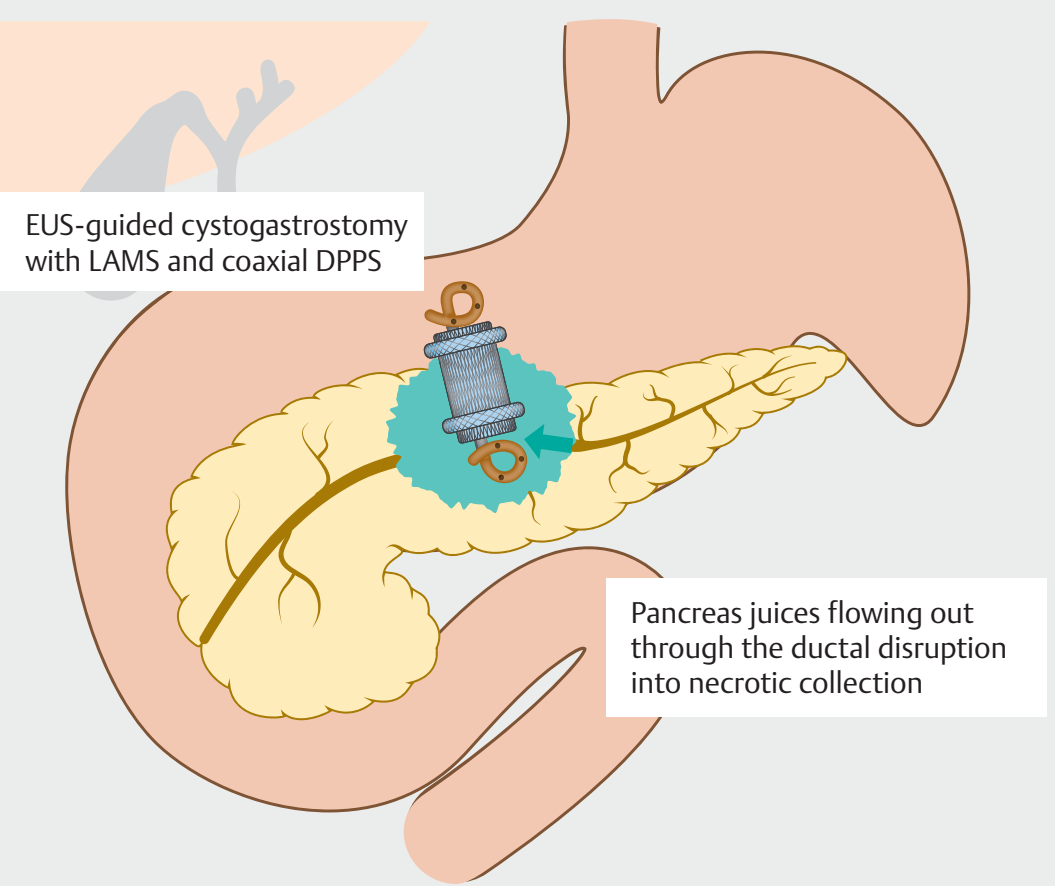

- Fig. 2 EUS-guided cystogastrostomy of necrotic fluid collection as treatment for disconnected pancreatic duct syndrome.

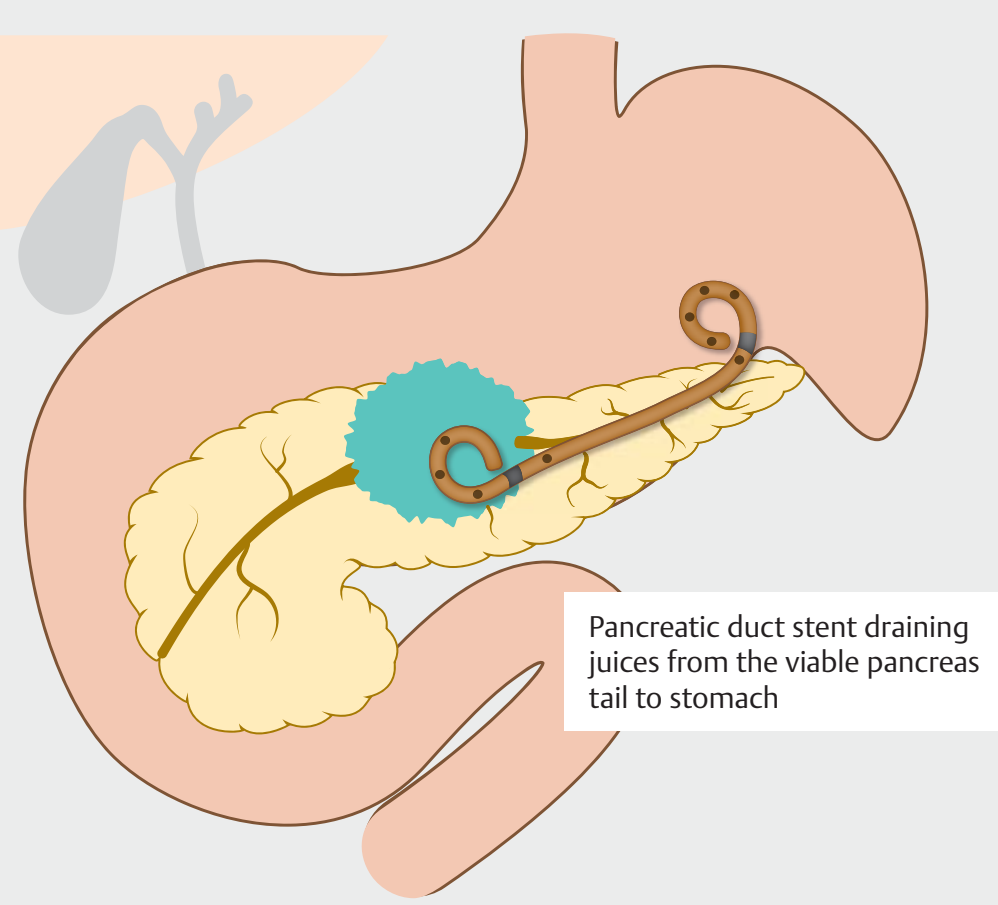

Fig. 5 Endoscopic-guided pancreaticogastrostomy facilitated by communicating mixed fluid collection.

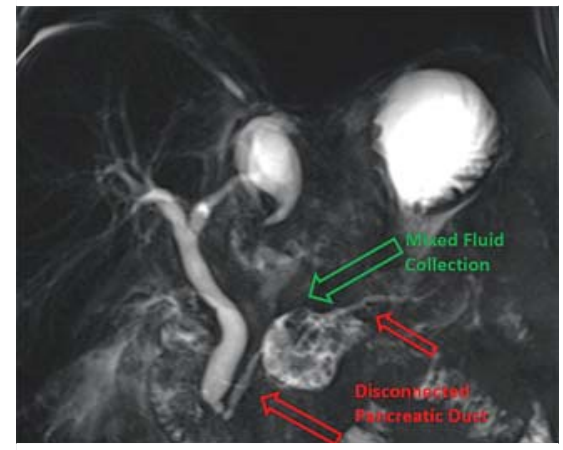

Fig. 3 Secretin-stimulated magnetic resonance cholangiopancreatography showing disconnected pancreatic duct syndrome.

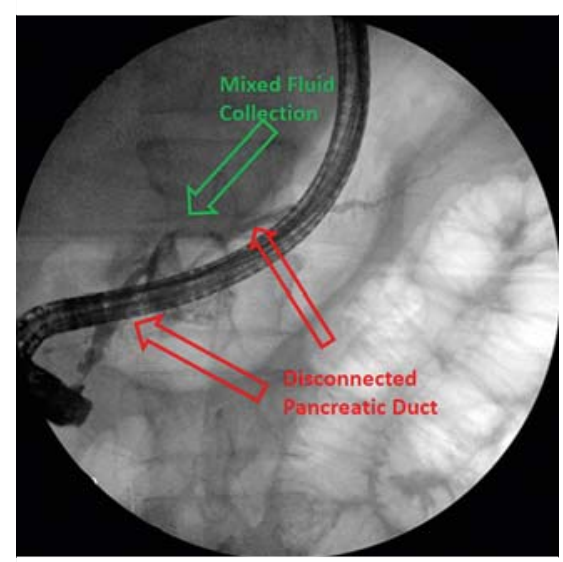

Fig. 4 Fluoroscopic view demonstrating disconnected pancreatic duct syndrome.

main pancreatic duct in the tail. However, EUS-guided pancreaticogastrostomy was not feasible owing to acute angulation between the main pancreatic duct and the needle. Given the communication between the duct and the necrotic collection into which the pancreatic juices from the upstream viable pancreas were flowing, a transgastric approach was chosen to drain the collection ( $\mathbf{F i g . 2}$ ). Under EUS guidance, a $15 \times 10-\mathrm{mm}$ lumen-apposing metal stent (LAMS) was deployed into the collection along with a coaxial $7 \mathrm{Fr} 5-\mathrm{cm}$ double-pigtail plastic stent. Repeat imaging 2 months later revealed the resolution of the necrotic collection, so the LAMS was removed and the stent left indefinitely for treatment of disconnected pancreatic duct syndrome. 
The second patient is a 63-year-old man presenting with recurrent acute pancreatitis. Computed tomography (CT) imaging of the abdomen revealed a $3.5-\mathrm{cm}$ mixed fluid collection in the pancreatic neck and a mildly dilated main pancreatic duct at the tail. On secretin-stimulated magnetic resonance cholangiopancreatography (MRCP), the main pancreatic duct was seen traveling into and out of the fluid collection but not within it (>Fig.3), suggesting its complete disruption (disconnected pancreatic duct syndrome). Wire placement across the disruption during endoscopic retrograde cholangiopancreatography (ERCP) was unsuccessful ( $>$ Fig.4). EUS-guided pancreaticogastrostomy was considered and contrast was injected into the dilated duct in the tail. The fluid collection also filled with contrast, indicating communication with the main pancreatic duct. A 0.025-inch guidewire was advanced through the duct in the tail and was allowed to coil within the collection. A 7 Fr 9-cm double-pigtail plastic stent was then deployed into the duct and the collection, creating the pancreaticogastrostomy ( $\triangleright$ Fig. 5).

Neither patient had any recurrence of acute pancreatitis on 6-months followup.

In these two cases, the presence of a fluid collection in communication with the dis- rupted main pancreatic duct rendered a technically challenging EUS-guided pancreaticogastrostomy more feasible and successful using an EUS-guided cystogastrostomy.

Endoscopy_UCTN_Code_TTT_1AS_2AD

\section{Competing interests}

Mouen A Khashab is a consultant for Boston Scientific, Apollo, Olympus America, Medtronic and GI Supply. All other authors have no disclosures.

The authors

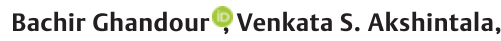
Michael Bejjani, Daniel Szvarca, Mouen A. Khashab

Division of Gastroenterology and Hepatology, Johns Hopkins Hospital, Baltimore, Maryland, United States

\section{Corresponding author}

\section{Mouen A. Khashab, MD}

Division of Gastroenterology and Hepatology, Johns Hopkins Hospital, 1800 Orleans St., Baltimore, MD 21287, USA

Fax: + 1 443-683-8335

mkhasha1@jhmi.edu

\section{Reference}

[1] Nadkarni NA, Kotwal V, Sarr MG et al. Disconnected pancreatic duct syndrome: endoscopic stent or surgeon's knife? Pancreas 2015; 44: 16-22

\section{Bibliography}

Endoscopy 2022; 54: 917-919

DOI 10.1055/a-1633-2762

ISSN 0013-726X

published online 1.10 .2021

(c) 2021. Thieme. All rights reserved.

Georg Thieme Verlag KG, Rüdigerstraße 14,

70469 Stuttgart, Germany

\section{ENDOSCOPY E-VIDEOS}

https://eref.thieme.de/e-videos

口回 Endoscopy E-Videos is a free

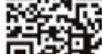
access online section, reporting on interesting cases and new

techniques in gastroenterological endoscopy. All papers include a high quality video and all contributions are freely accessible online.

This section has its own submission website at https://mc.manuscriptcentral.com/e-videos 